\title{
Parque indígena do xingu: efeitos do modo de vida urbano e da urbanização no território indígena
}

Maria Lucia Pires Menezes - Mestre em Geografia pela Universidade Federal do Rio de Janeiro (UFRJ) e doutorado em Geografia pela UFRJ e pela Universitat de Barcelona. Líder do Grupo de Pesquisa da Amazônia e Professora da Universidade Federal de Juiz de Fora.

\section{Resumo}

O Parque do Xingu emerge de um longo processo de luta entre instituições do Estado brasileiro e setores da sociedade civil, envolvendo o controle territorial e a privatização de terras. A superfície do Parque localiza-se na bacia do alto rio Xingu no Estado de Mato Grosso, território marcado pela presença de muitas etnias indígenas. Considerandose a configuração do Parque Indígena do Xingu em relação ao território matogrossense, constata-se que ele se encontra "ilhado" pois sofre pressões constantes da ocupação do seu entorno por grandes fazendas do agronegócio, pela mobilidade dos trabalhadores rurais e aparecimento de novas cidades. Recentemente uma série de fatos e eventos circunscritos à área de localização e de influência da terra indígena tem sido relacionada ao grande projeto da Infraestrutura Regional Sul-Americana (IRSA). Tal processo, como mostrado neste artigo é mutuamente reforçado pelo aumento da integração econômica regional, comercial, financeira e produtiva.

\section{Palavras-Chave}

Parque Indígena do Xingu, territorialidades, conflitos, Estado.

\section{Abstract}

Xingu National Park emerges from a long process of struggles between Brazilian Government institutions and sectors of the Civil Society, involving the territorial control and the privatization of land. The surface of the Park is located in the basis of the high Xingu River in the State of Mato Grosso, territory marked by the presence of several indigenous ethnic groups. Considering the configuration of the Xingu Indigenous Park in relation to the territory of Mato Grosso, one notices that it is "isolated" because it constantly suffers pressures of having its surroundings occupied by major farms of the agribusiness, by rural workers mobility and by the emergence of new towns. Recently, a series facts and events circumscribed to the area of localization and the influence of the indigenous land has been related to the big project of the South American Regional Infra-Structure (Infraestrutura Regional Sul-Americana - IRSA). This process, as presented in this article, is mutually reinforced by the increase of the regional, commercial, financial and productive economical integration.

\section{Keywords}

Xingu Indigenous Park, territorialities, conflicts, State. 


\section{INTRODUÇÃO}

A criação do Parque do Xingu resultou de um longo processo de luta entre instituições do Estado brasileiro e setores da sociedade civil, envolvendo o controle territorial e a privatização de terras. A superfície do Parque corresponde a uma parcela da vasta região - a bacia do alto rio Xingu no Estado brasileiro de Mato Grosso - onde se encontrava, já no início do século XX, uma variedade significativa de etnias indígenas localizadas. A partir dos anos 40, foi sendo sistematizado o contato entre setores da sociedade nacional, mais precisamente indigenistas, e os grupos indígenas.

Um posto de assistência do órgão oficial encarregado da tutela dos grupos indígenas no Brasil - o Serviço de Proteção aos Índios (SPI) - foi criado e instalado no Alto Xingu. Em 1952, foi apresentado ao Congresso Nacional um anteprojeto para a criação de um parque nacional na referida região (BRASIL, 1954). Nesse projeto, estava previsto um perímetro bem maior que o atual, incluindo uma zona tampão para amortecimento do contato com as frentes de expansão, proteção das nascentes da bacia hidrográfica e preservação do meio ambiente, imediatamente circunvizinho à região ocupada pela população indígena (MENEZES, 2000).

Em 1961, foi criado pelo governo federal no Alto Xingu o Parque Nacional do Xingu. Em 1973, por força do Estatuto do Índio, o Parque tem sua condição jurídica alterada para parque indígena. A Lei n. ${ }^{\circ}$ 6001/73, em seu artigo 28, define: "Parque Indígena é a área contida em terra para posse dos índios, cujo grau de integração permita assistência econômica, educacional e sanitária dos órgãos da União, em que se preservem as reservas de flora e fauna e as belezas naturais da região". Em virtude do novo status, o Parque do Xingu passou a ser subordinado à Fundação Nacional do Índio (FUNAI), deixando, portanto, de ser subordinado ao Instituto Brasileiro do Meio Ambiente e dos Recursos Naturais Renováveis (IBAMA), órgão do qual dependem os parques nacionais. Segundo a legislação ambiental brasileira, parques nacionais correspondem "a áreas geográficas extensas e delimitadas, dotadas de atributos naturais excepcionais, objeto de preservação permanente, submetidas à condição de inalienabilidade e indisponibilidade de seu todo". Considerando-se a configuração do Parque Indígena do Xingu (PIX) em relação ao território mato-grossense, constata-se que ele se encontra "ilhado". Isso porque o Parque do Xingu sofre pressões constantes sobre sua geografia e sua população, por causa da ocupação do seu entorno por grandes fazendas do agronegócio, da mobilidade dos trabalhadores rurais e das novas cidades.

Ao longo dos últimos 60 anos, a consolidação do espaço rural e urbano do Estado de Mato Grosso resultou na expansão espacial da economia para o interior 
do Brasil, o que provocou impactos socioambientais, especialmente no conjunto de etnias localizadas no Parque Indígena do Xingu. A ampliação do Parque Indígena do Xingu é atualmente uma das principais reivindicações de líderes indígenas endereçadas à FUNAI. O Parque tem quase 30 mil quilômetros quadrados, embora seu território atualmente seja muito menor do que o inicialmente previsto. Nas quatro décadas seguintes a sua criação, incorporou algumas pequenas áreas, porém não o suficiente para incluir as nascentes da bacia hidrográfica e evitar a pressão do desmatamento e da progressiva influência do complexo do agronegócio. A leitura do atual mapa de uso e ocupação de Mato Grosso revela a vulnerabilidade do Parque do Xingu e de seus habitantes em relação ao entorno ligado ao uso das terras pelo agronegócio. Esta pesquisa está começando e apresenta uma primeira leitura da análise geográfica do Parque Indígena do Xingu nos tempos atuais.

A configuração territorial do atual Parque do Xingu revela-se nos dados empíricos que permitem iniciar a análise do processo de instauração do modo de vida urbano (LEFEBVRE, 1999, 2001) e da consequente urbanização do território (FOUCAULT, 2006). No jogo de forças e lutas nas diversas instâncias do Estado e na arena de suas alianças com os setores privados da economia para a construção e a consolidação do complexo agroindustrial exportador sul-americano (MOREIRA, 2004), insere-se de modo especial a situação das terras indígenas do território brasileiro.

Recentemente uma série de fatos e eventos circunscritos à área de localização e de influência da terra indígena tem sido relacionada aos equipamentos do território e à mobilidade da força de trabalho, fatos que se inserem no grande projeto da Infraestrutura Regional Sul-Americana (IRSA). Consolidando-se como liderança regional, o Brasil passa a investir e a coordenar um programa de integração da infraestrutura regional (IRSA) com o apoio das instituições multilaterais (Banco Interamericano de Desenvolvimento (BID), Banco Internacional para a Reconstrução e o Desenvolvimento (Bird), Corporação Andina de Fomento (CAF) e agências de desenvolvimento europeias, japonesas etc.).

Tal processo é mutuamente reforçado pelo aumento da integração econômica regional, comercial, financeira e produtiva. E o Parque do Xingu está bem no âmago e no centro dessas territorialidades. O efeito mais imediato, conforme os dados que serão apresentados, é a urbanização do território. Com base nos dados referentes aos impactos socioambientais presentes na atualidade do território indígena, examinam-se três condições: a geografia do território oficial do parque do Xingu, o significado da transformação de parque nacional em parque indígena e os efeitos do processo de urbanização extensiva e da consolidação do agronegócio nas etnias e em seus descendentes localizados no referido território 
indígena. Esta pesquisa é uma contribuição para a gestão do território indígena na sociedade brasileira contemporânea. Já no final dos anos 70, os efeitos das frentes de expansão da fronteira agrícola, da criação de novos municípios e das novas cidades configuram um novo espaço-tempo para o parque. $\mathrm{Na}$ verdade, a consolidação do modelo de expansão do capitalismo monopolista implantado pela ditadura militar faz-se em ritmo acelerado, a despeito da precariedade inicial dos equipamentos territoriais. No entanto, a política de colonização dirigida, os incentivos fiscais e as linhas de crédito e financiamentos bancários em terras cujo valor relativo às áreas de agricultura consolidada, incentivou a migração de fazendeiros, especialmente do Sul-Sudeste do Brasil para as terras mato-grossenses. Ainda na ditadura, projetam-se estradas, sendo duas as que exercerão influência direta sobre o Parque do Xingu: a BR-158 (de Altamira no Pará até a fronteira com o Uruguai) a leste e a BR-163 (Cuiabá-Santarém) a oeste. A consolidação dos fixos impulsiona os fluxos para a região. Em menos de 20 anos, são criados 19 municípios no entorno do Parque do Xingu, todos ligados à chegada de empresas colonizadoras e grandes agropecuárias. Ao longo destes anos, muitas transformações ocorreram no âmbito da administração pública, da economia regional e, principalmente, nas relações políticas entre os grupos indígenas, o Estado e as organizações civis. Tais mudanças estão relacionadas à nova inserção da América Latina na ordem globalizada, quando se consolida a posição do Brasil como principal economia continental, expressa, por exemplo, nas políticas de cooperação econômica e na intensificação da participação da economia nacional na divisão internacional do trabalho. Do ponto de vista político-administrativo, as reformas institucionais iniciadas no governo Collor redesenham um novo papel do Estado e, nos governos FHC e Lula, refazem a estrutura governamental. Aposta-se no projeto de alavancar o setor agroindustrial, e são, então, retomados investimentos em infraestrutura viária e no aproveitamento da matriz energética, com a presença de grandes empresas, principalmente no setor agropecuário e mineral da economia desenvolvida em território brasileiro. Como resultado imediato, intensifica-se o crescimento das economias regionais e das articulações econômicas intracontinentais; por conseguinte, há impactos na mobilidade da força de trabalho, na urbanização do território e também impactos socioambientais.

Assim, as condições que alicerçaram a vida intertribal no Alto Xingu são influenciadas pela dinâmica sociopolítica da atual conjuntura. As alterações drásticas das condições geográficas, as novas logísticas de localização das aldeias indígenas, portanto, a socialização e a troca de bens e mercadorias são substituídas, agora, cada vez mais, pelo mercado de bens, mercadorias e serviços com a sociedade capitalizada exterior ao território indígena. 


\section{OS EFEITOS DA URBANIZAÇÃO E DA MODERNIZAÇÃO DA AGRICULTURA NO MATO GROSSO}

Ao longo dos últimos 30 anos, o processo de incorporação das terras matogrossenses à agricultura capitalista evolui muito rapidamente: passa-se das frentes de colonização dirigida para a agricultura comercial e a consolidação do agronegócio. As mesmas características geomorfológicas descritas acima para a bacia do Alto Xingu favorecem a extração de renda diferencial, em função, principalmente, da topografia suave e da consequente possibilidade de mecanização plena do sistema agrícola desenvolvido e adotado pelo complexo do agronegócio. Para o Instituto Socioambiental (ISA), a população indígena no Brasil atual está estimada em 600 mil indivíduos, e cerca de 480.000 mil desse total vivem em suas terras indígenas (e, em menor número, em áreas urbanas perto delas), enquanto outros $120.000 \mathrm{mil}$ encontram-se residindo em diversas capitais do país. É importante ressaltar que os dados do IBGE (Censo Populacional de 2000) indicaram que a parte da população brasileira que se autodeclarou genericamente como "indígena” alcançou a marca de 734 mil pessoas, marca, portanto, superior à estimada pelo ISA.

É em Lefebvre (1999, 2001) que vamos encontrar a explicação para a emergência do rural "urbanizado" e suas consequências na sociedade em transformação, pois, para o autor, a "sociedade urbana" nasce da industrialização que domina e absorve a produção agrícola e ao mesmo tempo se distancia do mundo rural. É o pleno comando da sociedade urbana gestada e articulada nas redes globais que explica, por exemplo, o alto índice de urbanização de Mato Grosso, a velocidade de alterações na estrutura de produção agrícola e seus reflexos na sociedade indígena do Alto Xingu.

Desde que a ciência, a tecnologia e a informação passaram a constituir as mais marcantes forças produtivas, o homem imprimiu intensa velocidade de renovação às forças produtivas e, dessa forma, passa a ter grande poder de interferência na natureza. Essas novas possibilidades modificaram radicalmente a relação homem-natureza. Desse modo, o homem, que já foi mero observador da natureza, passa a agente, com profunda capacidade de interferência nela, e constrói, com grande velocidade, uma segunda natureza, uma natureza artificializada, na qual os fixos artificiais são cada vez mais numerosos (ELIAS, 2006, p. 3).

As cabeceiras dos formadores do Xingu e o entorno do perímetro do Parque tornaram-se grandes fazendas empresariais. Tal estrutura é alicerçada por cidades que são o suporte financeiro-bancário e técnico-comercial da organização da produção. O primeiro impacto diz respeito ao desmatamento, e seguem-se os efeitos da esterilidade ou mesmo a impossibilidade cada vez maior da produção 
de cultura rural, pois toda a referência de consumo e trabalho parte agora da sociedade urbana. Essa sociedade expande-se para muito além das fronteiras da cidade, impondo um novo padrão de vida, calcado cada vez mais no modelo da sociedade urbana monopolística. Internamente as etnias vivem o confronto com a modernidade tecnológica, que traz mercadorias e novos meios técnicocientíficos para seus espaços e territórios. Isso pode ser percebido nas crescentes formas de conflitos de geração envolvendo os jovens e as lideranças, normalmente representadas por homens mais velhos e testemunhas da história dos últimos 50 anos do Alto Xingu. A cidade e o urbano estão cada vez mais presentes e mais próximos, dentro das aldeias, participando do cotidiano de todos. O documentário Xingu: uma terra ameaçada (1985), do jornalista Washington Novaes, é capaz de identificar as tensões dos tempos nos espaços de vida das diversas etnias que habitam o Xingu.

Um outro dado a ser considerado é a estrutura institucional à qual o Parque Indígena está vinculado. Se comparada, por exemplo, ao IBAMA, a FUNAI hoje é um órgão enfraquecido politicamente, sucateado e sem aporte de verbas suficiente para a implementação de novos projetos, para a atualização e a qualificação do quadro funcional, para a implantação de políticas sociais . Tornase, assim, importante constatar a importância de uma política de ações para a inserção e a vivência dos grupos indígenas diante do novo modelo de sociedade, pautado pela inserção do Brasil na economia global, e de região, cada vez mais urbanizada. Embora esta seja uma primeira abordagem da temática, pretende-se futuramente analisar a presença do urbano dentro ou nas circunvizinhanças dos territórios indígenas, numa perspectiva de análise diferente das pesquisas que enfatizam a problemática urbana a partir da localização dos índios na cidade. Acreditamos ser importante lutar pelo empoderamento das instituições públicas no que tange à problemática indígena, construindo-se uma política de ação com base em abordagens que privilegiem a inserção das etnias na sociedade urbana nacional e a preservação da cultura consolidada no tempo e na geografia de vivência dos povos do Alto Xingu. A Constituição Federal de 1988 garantiu aos povos indígenas o direito a uma política educacional específica, regulamentada em torno de atributos como o uso da língua materna e a construção de currículos adaptados à tradição dos povos indígenas. Mais recentemente, definiram-se políticas de cotas nas universidades públicas que buscam atender a formação de índios e professores indígenas.

A consolidação de Mato Grosso como grande produtor de grãos e, mais recentemente, a aplicação de uma política de incentivos à produção de biocombustíveis inserem a problemática das terras indígenas em uma nova 
geopolítica. A pressão sobre o uso produtivo agrícola sob um modelo tecnológicoexportador força as terras indígenas a fazerem parte do arranjo espacial articulado ao sistema urbano nacional, continental e global. No caso do PIX, uma constelação de cidades, de sedes municipais consolidou-se, ao longo dos últimos 30 anos, como lócus das decisões políticas e econômicas de ação na instância local da produção.

O crescimento da população regional é sobremaneira incentivado pelas políticas de ocupação e de empresariamento das terras por meio do agronegócio e da consequente urbanização do Centro-Oeste. Pode-se tomar, então, o território do Parque como uma reserva de recursos representados pelo próprio estoque de terras, pelos recursos ambientais e pela histórica pressão sobre a reserva de força de trabalho que a população indígena representa e constitui. No entanto, esse processo tem dois sentidos: de um lado, o mundo urbano e urbanizante do atual modelo de governo e de gestão do território; de outro, a sociedade indígena xinguana como reserva de mercado e com suas próprias demandas sociais, culturais e ambientais no seio do parque indígena. Consequentemente, retoma-se a luta entre o território indígena e o estoque de terras agricultáveis. Tal processo é acompanhado de discursos ideologizados sobre a iminência da perda da soberania territorial adiante da possibilidade de autodeterminação dos povos indígenas sobre as terras, ou do "perigo" de interferências de outros agentes pretensamente contrários aos interesses de Estado. Recentes conflitos envolvendo a Terra Indígena Raposa do Sol em Roraima exemplificam os embates entre setores que advogam o uso das terras segundo o modelo privativo econômico e os setores que defendem o Estado enquanto agente mantenedor da soberania territorial e responsável pela gestão do território, preferencialmente realizada por instituições estatais. Sendo as terras indígenas consideradas terras da União, frequentemente há acusações de federalização das terras de estados e municípios do território brasileiro. Alguns setores sociais, em uma atitude extrema, são capazes de qualificar de inconstitucionais extensas áreas de propriedade da União, como no caso da Raposa Terra do Sol, onde há sobreposição de terras indígenas e faixa de fronteira, fato nunca antes questionado, visto que, durante a ditadura militar, a faixa de fronteira foi considerada como área de segurança nacional.

Uma outra crítica frequente diz respeito à participação de organizações não governamentais (ONG) em diversos projetos envolvendo terras e grupos indígenas. No caso específico do Parque do Xingu, o Instituto Socioambiental (ISA) tem atuado sistematicamente na região por meio de inúmeros projetos e parcerias que, na verdade, revelam a necessidade da participação de outros agentes e atores, dada a complexidade da questão indígena no Brasil. Por outro 
lado, verifica-se uma ação muito débil, a despeito do conjunto de leis existentes para orientar a atuação do Estado na garantia dos direitos dos índios. Um dado importante a ser considerado diz respeito à história social do Alto Xingu, que abriga uma população com relativa diversidade etnolinguística e cultural. A diversidade linguística, de um lado, e as similaridades socioculturais, de outro, confirmam a necessidade de fazer do Xingu um parque indígena. Hoje os grupos indígenas que habitam o PIX são considerados integrantes do "sistema xinguano". O compósito populacional abriga grupos tradicionalmente localizados na bacia do Alto Xingu e diversos grupos transferidos por ação indigenista oficial (MENEZES, 2000). A Constituição Federal de 1988 estabeleceu, no Capítulo VIII, garantiu aos índios: o reconhecimento de sua organização social, de seus costumes, de suas línguas, crenças e tradições; seus direitos originários e imprescritíveis sobre as terras que tradicionalmente ocupam, consideradas inalienáveis e indisponíveis; a posse permanente sobre essas terras; o usufruto exclusivo das riquezas do solo, dos rios e dos lagos nelas existentes; o uso de suas línguas maternas e dos processos próprios de aprendizagem; proteção e valorização das manifestações culturais indígenas, que passam a integrar o patrimônio cultural brasileiro. No que tange às especificidades dos parques indígenas, vale salientar que o artigo 28 do Estatuto do Índio, que trata dos parques indígenas, determina:

$\S 1^{\circ} \mathrm{Na}$ administração dos parques serão respeitadas a liberdade, usos, costumes e tradições dos índios.

$\S 2^{\circ}$ As medidas de polícia, necessárias à ordem interna e à preservação das riquezas existentes na área do parque, deverão ser tomadas por meios suasórios e de acordo com interesse dos índios que nela habitam.

$\S 3^{\circ} \mathrm{O}$ loteamento das terras do parque indígena obedecerá ao regime de propriedade, usos e costumes tribais, bem como às normas administrativas nacionais, que deverão ajustar-se aos interesses das comunidades indígenas.

Não há dúvida de que a legislação preserva e garante os direitos dos indígenas. Considerando-se o reconhecimento por parte de variados segmentos sociais, tanto nacionais quanto internacionais, o Parque do Xingu ainda é um modelo (FREIRE, 1986) bem-sucedido de gestão da população e do território indígena. O Estado nacional é aí o agente principal em função da história da política oficial brasileira de assistência e proteção das populações indígenas. No entanto, o tempo não passa em vão, mesmo com toda a ideologia dominante sobre o congelamento do ser índio que caracteriza a compreensão vulgar e banal da sociedade nacional. São inegavelmente mais visíveis e veiculados pelos meios de comunicação os impactos ambientais, relegando-se a segundo plano - ou mesmo 
inexistindo - a percepção das transformações no comportamento dos grupos indígenas adiante da velocidade das transformações empreendidas no território em consequência da urbanização imposta pelo modo de produção. Assim, o território localizado em um ecossistema extremamente rico em biodiversidade e povoado por um conjunto de etnias diversas transforma o Parque do Xingu num cosmo de suma importância sociopolítica e geopolítica.

A própria visão geopolítica parte agora do interior do parque para os arredores. Basta observar a quantidade de postos indígenas de vigilância (PIV). No Parque, reproduz-se a lógica de defesa de limites de território, adotada pelos militares nos limites do Brasil com os países limítrofes, por meio dos postos de fronteira. No entanto, a localização dos PIV preferencialmente ribeirinha isto é, na rota de acessibilidade do parque - torna também esses postos zonas obrigatórias de contato. No PIX, há três grandes postos indígenas localizados nas três sub-regiões em que se pode dividir a bacia do Xingu: o alto Xingu, sob a administração do posto indígena (PI) Leonardo, o médio parque, sob a jurisdição do PI Pavuru, e o norte, onde se localiza o PI Diauarum. A função do posto indígena é centralizar a administração da FUNAI na terra indígena, sendo o chefe de posto designado por portaria e detentor de cargo de confiança. Oficialmente, compõem as funções do posto: coordenar as ações de saúde, de educação e as ações de promoção do desenvolvimento socioeconômico do grupo indígena e, também, assegurar a proteção e a vigilância do território indígena. Há de se salientar o caráter político dessa função e imaginar as articulações políticas a que o cargo está sujeito, já que pode ser ocupado tanto por funcionários do quadro institucional da FUNAI, quanto por outro funcionário público, mas, principalmente, por chefes indígenas ou por outro membro destacado do grupo étnico. Passados anos e intensificando-se as relações com diferentes atores da sociedade envolvente, produz-se um processo político-pedagógico que reflete não apenas as relações dos grupos indígenas com a exterioridade nacional e internacional, mas também os efeitos das relações intraétnicas dos habitantes do Parque do Xingu. Informa o Instituto Socioambiental:

Nos últimos anos, foram criadas no PIX cinco associações e, ao que parece, este número deve aumentar. Das existentes, três estão ligadas a interesses locais de aldeias específicas: Mavutsinim, dos Kamaiurá; Jacuí, dos Kalapalo, bem como a associação dos Wauja. Em 1994, foi criada a Atix (Associação da Terra Indígena do Xingu), que abrange as 14 etnias do Parque, atendendo a interesses interlocais. Na sua pauta, constam projetos de revitalização cultural, proteção e fiscalização do território, além de programas de educação, saúde e alternativas econômicas. A Atix conta com apoio institucional da Rainforest Foundation da Noruega e assessoria do ISA (VILLAS BÔAS, 2002). 
Na verdade, essas associações são politicamente necessárias. Para comprovar isso, basta lembrar o que já foi dito: a organização interna do PIX está baseada na interdependência econômica; o sistema de parque indígena é importante para assegurar uma convivência pacífica; o estoque de recursos e de bens presentes no interior do parque não é mais o mesmo, ao contrário, está sofrendo os efeitos do impacto ambiental e do processo de urbanização ao redor do parque. A análise desse processo representa uma oportunidade de pesquisa acadêmica, no sentido de verificar propostas comunitárias ou compartilhadas pelas diferentes etnias para o rearranjo político com possíveis implicações espaciais na gestão de seu território de convivência.

\section{O URBANO NA ALDEIA: TEMPOS CONTRÁRIOS E ESPAÇOS DIALÉTICOS}

É impossível não se surpreender com a velocidade da urbanização e a quantidade de novas cidades que surgiram no Estado de Mato Grosso, como em toda a Amazônia, nestes últimos 30 anos. No entender de Monte-Mór (2004), nas cidades, concentram-se as possibilidades de acesso às facilidades da vida moderna, à cidadania, enfim, à urbanidade e à modernidade. Essa mesma realidade geográfica inclui um contingente diverso e rico, cultural e etnicamente representado por sociedades indígenas, cuja população a FUNAI estima em 30.000 (dados do Censo 2000) no Estado de Mato Grosso. O aumento populacional não foi acompanhado de plena cidadania, autodeterminação e melhoria das condições de vida dos grupos indígenas, embora os movimentos políticos e sociais tenhamse ampliado, especialmente ao final do período ditatorial no Brasil. Um novo modelo de flexibilização da atuação do órgão de proteção oficial, novos atores assumindo o sistema de assistência e novas carteiras de financiamento de projetos para a causa indígena traçam um mapa extremamente variado das conquistas dos grupos indígenas brasileiros, mais pulverizados e mais dependentes da solução e da aliança com o quadro regional no vasto território brasileiro. Por outro lado, a maior intimidade com a sociedade urbana e o exercício do trabalho, ou mesmo a inserção informal no complexo agroexportador, resultaram numa maior submissão à sociedade e à economia regional. $\mathrm{O}$ fato de a rede de cidades propiciar e induzir a existência das condições gerais de produção necessárias à realização do modelo capitalista monopolista de produção e extração de renda do campo no Brasil contribui, simultaneamente, para a ampliação do tecido urbano (LEFEBVRE, 1999) e a instauração do domínio do urbano sobre o campo. Incluem-se mais precisamente nesta pesquisa os efeitos da urbanização nos territórios indígenas. 
Quando se escolhe o Parque Indígena do Xingu como um recorte espacial possível de análise, descobrem-se infinitas possibilidades de examinar os tempos diferenciais da sociedade e as espacialidades e territorialidades possíveis na construção da cultura e no fortalecimento político da sociedade indígena. Ela está diante, por exemplo, do atual governo estadual sob o comando de um grupo familiar que é um dos maiores exportadores de soja do mundo (Grupo Maggi), presente naquele espaço. Ao mesmo tempo é na cidade - materialidade logística do urbano - que se organiza o "movimento" e as associações políticas responsáveis pelas diversas formas de mobilização social, inclusive pela luta em prol da causa indígena. É na cidade que está a interação, é na cidade que se encontra o outro e os outros. Simultaneamente, o urbano que se desloca e se introduz na aldeia faz gerar novas possibilidades, mas também novos embates e conflitos numa dinâmica de construção da cultura, que não pode prescindir da cidade e do urbano, muito menos da natureza e do conhecimento acumulado em gerações de comunidades indígenas.

O Estatuto do Índio, quando define parque indígena, sua importância e suas funções, permite que se reconheça que "O tempo não é abstrato, como o relógio deixa transparecer, mas está inscrito nas coisas, daí a complexidade dos espaços, que comportam sempre, diferentes temporalidades convivendo" (GONÇALVES, 2007, p. 405). Assim, é preciso que se consagrem e se ampliem as conquistas dos índios na sociedade nacional, sem que isso implique revisionismos contrários aos direitos adquiridos; é preciso que se amplie a participação política das representações indígenas, mesmo considerando a existência de uma vasta gama de formas de representação possíveis e existentes na sociedade indígena, oriundas das diferentes geografias locais e regionais. A capacidade civil dos índios ainda é uma questão complexa e delicada, assim como a supressão imediata do instituto da tutela. É preciso aprofundar o processo político-pedagógico de garantir aos povos indígenas o direito à autoidentificação e à autodeterminação. As notícias abaixo relacionadas exemplificam as diferentes expressões da urbanização e do mundo urbano, esteja ele na cidade ou não:

O herdeiro chefe Marica Kuikuro usa roupas em parte do tempo e fala português, tem e.mail, namora uma moça de "fora", anda de moto e já teve [sic] em várias capitais estaduais. Ele é integrante do coletivo Kuikuro de cinema e afirma que quer alternar a vida na aldeia e na cidade (www. agenciabrasil.gov.br, 10 ago. 2007).

Cerca de 50 índios da etnia Kayapó, do Parque Indígena do Xingu, invadiram a prefeitura de Colíder, no norte de Mato Grosso, em protesto contra o fechamento do único aeroporto do município [...]. Segundo os líderes da 
ocupação, os caciques Raoni e Megaron Txukarramãe, as etnias do Xingu podem ser prejudicadas no abastecimento de alimentos e remédios (www. ambientebrasil.gov.br, 5 mar. 2008).

Representantes Ikpeng reúnem-se com governo federal para discutir Pequenas Centrais Hidrelétricas (PCHs) na região das cabeceiras do Xingu depois de liberar 14 reféns. Lideranças xinguanas vão consultar comunidades sobre continuidade dos estudos da PCH Paranatinga II. [...] Do dia 20 ao dia 25 ficaram retidos na aldeia Moygu seis funcionários do órgão e oito consultores da Paranatinga Energia S.A. que coletavam dados sobre os efeitos para os povos indígenas da barragem, de responsabilidade da empresa. Todos foram soltos e levados para Cuiabá (www.sociabiental. org, 5 mar. 2008).

O IBAMA e a Polícia Federal iniciaram na madrugada desta quarta-feira a Operação Mapinguari, uma grande investida de fiscalização para reprimir desmatamento dentro do Parque Indígena do Xingu, a maior área protegida de Mato Grosso, com quase 3 milhões de hectares. Nesta operação foram constatados [sic] uma série de procedimentos irregulares envolvendo desde órgãos governamentais até a própria participação de indígenas na operação de contrabando de madeira. Nesta mesma matéria é relatado o caso do empresário Nei Frâncio, tido como o terceiro maior sojicultor do país e dono da colonizadora que fundou a cidade de Feliz Natal, e sua irmã Luciane FrâncioGaraffa,elestêminúmerasdenúnciasemsuascostasdeexploraçãodemadeira dentrodaterraindígena.[...]ambosestãosendoprocessadospeloMinistériodoTrabalho pormantertrabalhadoresemcondiçõesdegradantesemoutrasfazendasdosmunicípios de Vera e Feliz Natal (www.oeco.org.br, 16 maio 2007.)

Em 1 de novembro de 2007 noticia-se que [...] Já foram liberadas as 11 pessoas, entre funcionários da FUNAI e prestadores de serviços, que há 9 dias estavam retidos por índios da aldeia Pavuru no Parque Indígena do Xingu próximo à divisa dos estados de Mato Grosso e do Pará, sem acesso a barco ou avião para deixar o local [...]. Para Gecinaldo Satere Mawe, da Coordenação das Organizações Indígenas da Amazônia Brasileira (COIAB), o problema é reflexo da desestruturação e falta de recursos públicos da saúde e poderá ser agravado (www.radiobras.gov.br).

A geografia do Alto Xingu torna-se sobremaneira complexa. Os efeitos da dominância do modelo da empresa agrícola na produção da cidade e do urbano fazem-se notar nos exemplos supracitados. A cidade e o urbano representam um lugar da reprodução da força de trabalho, da viabilização do consumo por meio da produção e circulação de bens, serviços, informação e tecnologias. As lutas pela homogeneidade do tempo para a incorporação do modelo dominante fazem do Parque Indígena do Xingu um lugar especial e geopolítico. A geopolítica inscreve na terra dos índios a luta política pela terra de todos os homens. 


\section{REFERENNCIAS}

BRASIL. Congresso Nacional. Anteprojeto de lei de criação do Parque Indígena do Xingu. Rio de Janeiro, 1954.

ELIAS, Denise. Ensaios sobre os espaços agrícolas de exclusão. Revista Nera, Presidente Prudente, ano 9, v. 1, n. 8, p. 29-51, jan./jun. 2006.

FOUCAULT, Michel. Seguridad, territorio, población: curso en el Collège de France (1977-1978). Buenos Aires: Fondo de Cultura Económica, 2006.

FREIRE, Carlos Augusto da Rocha. Saudades do Brasil ou as lutas pela criação do Parque Indígena do Xingu. 1986. Trabalho apresentado ao curso de Problemas de Análise Etnológica do Programa de Pós-Graduação em Antropologia Social do Museu Nacional da Universidade Federal do Rio de Janeiro (2. ${ }^{\circ}$ semestre de 1986). Rio de Janeiro, 1986.

GONÇALVES, Carlos Walter. A invenção de novas geografias: a natureza e o homem em novos paradigmas. In: SANTOS, Milton et al. Territórios, territórios: ensaios sobre o ordenamento territorial. Rio de Janeiro: Lamparina, 2007. p. 375409.

LEFEBVRE, Henri. A revolução urbana. Belo Horizonte: UFMG, 1999.

O direito à cidade. São Paulo: Centauro, 2001.

MENEZES, Maria Lucia P. Parque Indígena do Xingu: a construção de um território estatal. 1990. Dissertação (Mestrado em Geografia) - Universidade Federal do Rio de Janeiro, Rio de Janeiro, 1990.

Parque Indígena do Xingu: a construção de um território estatal. Campinas: UNICAMP, Imprensa Oficial, 2000.

MONTE-MÓR, Roberto L. M. Urbanização e modernidade na Amazônia contemporânea. In: LIMONAD, Ester; HAESBAERT, Rogério; MOREIRA, Ruy (Org.). Brasil século XXI: por uma nova regionalização? São Paulo: Max Limonad, 2004. p. 112-122.

MOREIRA, Ruy. A nova divisão territorial do trabalho e as tendências de configuração do espaço brasileiro. In: LIMONAD, Ester; HAESBAERT, Rogério; MOREIRA, Ruy (Org.). Brasil Século XXI: por uma nova regionalização? São Paulo: Max Limonad, 2004. p. 123-152. 
VILLAS BÔAS, André. Xingu: associações indígenas. Dez. 2002. Disponível em: $<$ http://www.socioambiental.org/pib/.shtm>.

XINGU: uma terra ameaçada. Produção de Washington Novaes. 1985.

Documentário. Disponível em: <http://www.xingudoc 